\title{
POLIAFETIVIDADE E O ORDENAMENTO JURÍDICO BRASILEIRO: UMA NOVA FORMA DE FAMÍLIA FRENTE À UNIÃO ESTÁVEL E À INTERFERÊNCIA ESTATAL NA VIDA PRIVADA
}

\author{
POLIAFETIVITY AND BRAZILIAN LEGAL ORDINANCE: A NEW \\ FORM OF FAMILY AGAINST STABLE UNION AND STATE \\ INTERFERENCE IN PRIVATE LIFE
}

Maria Izabel Afonso PASTORI ${ }^{1}$

Maria Amália de Figueiredo Pereira ALVARENGA ${ }^{2}$

ISSUE DOI: $10.21207 / 1983.4225 .443$

\begin{abstract}
RESUMO
O presente artigo tem como finalidade principal a análise de uma nova configuração familiar presente no corpo social atual, formada a partir da união de mais de dois indivíduos, de forma concomitante, consensual e não excludente, distanciando-se do "convencional" modelo de família formado a partir do marido e mulher. Além disso, pondera acerca do modo sobre o qual este se insere na sociedade, levando em conta a maneira pela qual se dá a interferência do Estado na vida privada, bem como a
\end{abstract}

\footnotetext{
${ }^{1}$ Graduanda em Direito (4ºmestre). Universidade Estadual Paulista "Júlio de Mesquita Filho" - Faculdade de Ciências Humanas e Sociais. E-mail: mariaizabelpastori@ gmail.com

${ }^{2}$ Possui graduação em Direito pela Faculdade de Direito de Franca (1984), mestrado em DIREITO FHDSS (1994) e doutorado em Direito - FHDSS (1999). Avaliadora de curso e institucional do Ministério da Educação. Tem experiência na área de Direito, com ênfase em Direito Civil, atuando principalmente nos seguintes temas: novo código civil brasileiro, parte geral, direitos da personalidade, novo código civil e responsabilidade civil.
} 
respeito de seu reconhecimento como união estável e sua relação com a monogamia e com a liberdade de escolha. Por fim, aqui também cabe a análise da técnica da ponderação como uma possível solução para a questão; como também a reflexão a respeito da bissexualidade e da compersão, de modo a promover um maior esclarecimento frente ao preconceito e ao tradicionalismo, dominantes na sociedade atual.

Palvras-chave: poliafetividade; interferência estatal; monogamia; liberdade; união estável; ponderação.

\begin{abstract}
The main purpose of this paper is to analyze a new family configuration present in the current social body, formed from the union of more than two individuals, in a concomitant, consensual and nonexcluding manner, distancing itself from the "conventional" model family formed from the husband and wife. In addition, it ponders the way in which it is embedded in society, taking into account the way in which the State intervenes in private life, as well as regarding its recognition as a stable union and its relation to the monogamy and freedom of choice. Finally, it is also possible to analyze the weighting technique as a possible solution to the question; as well as the reflection on bisexuality and compersion, in order to promote greater clarification in the face of prejudice and traditionalism, dominant in today's society.
\end{abstract}

Keywords: polyactivity; state interference; monogamy; freedom; stable union; weighting.

\title{
INTRODUÇÃO
}

A natureza e o objetivo deste projeto de pesquisa é analisar um novo modelo de configuração amorosa e familiar formado a partir da união de mais de dois indivíduos, ou seja, distante da forma convencional do "marido e mulher". Além disto, ponderar acerca do modo sobre o qual este se insere na sociedade atual, levando em conta a maneira pela qual se dá a interferência do Estado na vida privada, bem como a respeito de seu reconhecimento como união estável. Segundo Cláudia do Nascimento Domingues, tabeliã que lavrou o documento que uniu três pessoas em Tupã, interior do Estado: "Só estamos documentando o que sempre existiu. Não es-

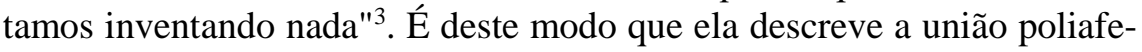
tiva ou poliamor, prática de construir relacionamentos conjugais estáveis com mais de uma pessoa, de forma concomitante, consensual e não excludente, que se constitui um tema deveras hodierno, sendo assim de extrema importância seu estudo.

Ademais, o poliamor como opção ou modo de vida, tutela a possibilidade de se estar envolvido de modo responsável em relações íntimas,

\footnotetext{
${ }^{3}$ DOMINGUES, Cláudia do Nascimento. União Poliafetiva. São Paulo, BBC Brasil, atualizado em 28 de agosto, 2012. Entrevista concedida á Jefferson Puff. Disponível em:< http://www.bbc.com/portuguese/noticias/2012/08/120828_ping_uniao_poliafetiva_jp.shtml>. Acesso em 18/11/2015.
} 
profundas e eventualmente duradouras com vários parceiros simultaneamente. Neste contexto, dois fenômenos são muito presentes: a bissexualidade (atração afetiva, seja ela sexual, romântica ou emocional, por pessoas de ambos os sexos, independentemente do gênero a que correspondem) e a compersão, este último pode-se traduzir como o oposto de ciúme: a capacidade de ficar feliz por outra pessoa estar feliz amorosamente, e não ser com você. Temas, que em conjunto com a obra e, em especial no primeiro capítulo, também serão abordados ao longo do estudo.

Entretanto, por ser tão contemporâneo, paira sobre o tema um embate entre os juristas brasileiros e os defensores do "amor livre", quanto à aceitação ou não pelas leis dessa nova forma de constituição de família. Tal teoria surgiu no seio do movimento anarquista, em conjunto com a rejeição da interferência do Estado e da igreja na vida e nas relações pessoais. Seus seguidores acreditam que a igreja e o Estado não têm o direito de definir o que deve ou não ser considerado um relacionamento amoroso. Defendendo a prática todo tipo de relação amorosa - inclusive a monogâmica - não atrelada a quaisquer registros formais, posse, controle ou nome. No século XX, alguns proponentes do amor livre alargaram a crítica à instituição do casamento argumentando que este encoraja a dependência psicológica. Destarte, o que se verifica é uma carência de legislação que especifique o seu lugar dentro do ordenamento jurídico brasileiro, bem como que estabeleça os limites da interferência estatal na vida privada, no que tange à defesa da sociedade. A consequência disso é o julgamento de acordo com a arbitrariedade e interpretação normativa de cada juiz.

Tendo isto em vista, o primeiro capítulo desta composição discorre acerca deste conceito que cada dia mais se sobressai na mídia, abordando suas origens, maneiras, definição, formação, dentre outros aspectos relevantes. Bem como a teoria do amor livre, já mencionada, e a qual é totalmente adaptada a este contexto, por se postar como defensora de qualquer tipo de relação amorosa.

Nesse ínterim, no segundo capítulo será discorrido sobre itens que adentram e participam desta constituição, por se encontrarem indissociados do objeto de estudo. Estes são: a monogamia e a liberdade de escolha. Posto isso, é possível verificar o dilema no qual eles se inserem: como harmonizar o princípio da monogamia consolidado no Código Penal, conforme o art. 235:

Contrair alguém, sendo casado, novo casamento: $\S 1^{\circ}$

- Aquele que, não sendo casado, contrai casamento 
com pessoa casada, conhecendo essa circunstância, é punido com reclusão ou detenção, de um a três anos. $\S 2^{\circ}$ - Anulado por qualquer motivo o primeiro casamento, ou o outro por motivo que não a bigamia, considera-se inexistente o crime. ${ }^{4}$

A liberdade de escolha é afirmada pelo art. $5^{\circ}$ da Constituição Federal: "Todos são iguais perante a lei, sem distinção de qualquer natureza, garantindo-se aos brasileiros e aos estrangeiros residentes no País a inviolabilidade do direito à vida, à liberdade, à igualdade, à segurança e à propriedade" .

Impasse que será examinado em conjunto e levando em consideração o modo de como o Estado, na sociedade moderna, interfere da vida privada dos indivíduos: os interesses da sociedade devem ser escudados, mas dentro de um direito privado, em que a autonomia das partes envolvidas deve prevalecer, pois, caso contrário, estar-se-ia interferindo na liberdade de escolha do cidadão, e, dessa maneira, não levando a uma real efetivação da justiça.

Frente a tal problemática, no terceiro capítulo há um aprofundamento da pesquisa sobre o papel da poliafetividade no ordenamento jurídico brasileiro. Ao que se tem em vista, este tipo de união se dá por escritura pública declaratória de união estável poliafetiva, o que gera alterações no conceito de família. E o qual, segundo a tabeliã e pesquisadora Cláudia: "Na minha visão, essa união poliafetiva não afeta o direito das outras pessoas" ", disse em entrevista à BBC Brasil.

A união estável é proclamada no ordenamento jurídico como objetivo de constituição familiar, segundo disposto no Código Civil Brasileiro: "Art. 1.723. É reconhecida como entidade familiar a união estável entre o homem e a mulher, configurada na convivência pública, contínua e

\footnotetext{
${ }^{4}$ CÓDIGO PENAL /[colaboração de Antonio Luiz de Toledo Pinto e Márcia Cristina Vaz dos Santos Windt]. - São Paulo: Saraiva, 1999, p. 489.

${ }^{5}$ CONSTITUIÇÃO DA REPÚBLICA FEDERATIVA DO BRASIL DE 1988. Brasília, DF, Senado, 1988. Disponíel em:< http://www.planalto.gov.br/ccivil_03/constituicao/constituicaocompilado.htm>; acesso em 26 de agosto de 2016; ás 00:09.

${ }^{6}$ DOMINGUES, Cláudia do Nascimento. União Poliafetiva. São Paulo, BBC Brasil, atualizado em 28 de agosto, 2012. Entrevista concedida á Jefferson Puff. Disponível em:< http://www.bbc.com/portuguese/noticias/2012/08/120828_ping_uniao_poliafetiva_jp.shtml>. Acesso em 18/11/2015.
} 
duradoura e estabelecida com o objetivo de constituição de família"7. Porém, mais do que isto, é também declarada a facilitação de sua conversão em casamento, tendo em vista o art.1.726: “A união estável poderá converter-se em casamento, mediante pedido dos companheiros ao juiz e assento no Registro Civil."”; do Código Civil, bem como o art. 226, § $3^{\circ}$, da Constituição Federal:" Para efeito da proteção do Estado, é reconhecida a união estável entre o homem e a mulher como entidade familiar, devendo a lei facilitar sua conversão em casamento"9.

Dessa maneira, após um profundo exame acerca de todas as perspectivas de tais artigos, explora-se uma possível e plausível resolução: a técnica da ponderação, que consiste em pautar as suas decisões na proporcionalidade, na necessidade, na adequação, o que também serviria de parâmetro para regular a interferência do Estado na vida privada, ao estabelecer a supremacia da igualdade material e da dignidade da pessoa humana. Uma vez que, como evidenciado acima, ao mesmo tempo em que está positivado o casamento, também está a união estável, que o próprio ordenamento faculta na conversão em casamento, deixando grandes expectativas sobre o ordenamento brasileiro acerca da aceitação de famílias poliafetivas poderem vir a contrair casamento nas próximas décadas.

Outrossim, ainda no capítulo três, apura-se um possível destino lamentável: a discriminação social e o preconceito frente ao não abarcamento pelas leis, deixando tais indivíduos em uma situação de extrema vulnerabilidade.

Por fim, posteriormente ao estudo dos capítulos mencionados, será concluído se é dever do Direito adaptar-se à constante mudança da sociedade brasileira da opção escolhida, no que tange à necessidade da criação de leis específicas para essa parcela da sociedade, para que, assim, haja uma maior aceitação e compreensão social, uma vez que na sociedade vigente, a poliafetividade é uma realidade que não pode mais ser refutada.

\footnotetext{
${ }^{7}$ BRASIL. Código Civil e Constituição Federal e legislação complementar: miniobra coletiva de autoria da Editora Saraiva com a colaboração de Luiz Roberto Curia, Livia Céspedes e Juliana Nicoletti. 21. ed.- São Paulo: Saraiva, 2015, p. 173.

${ }^{8}$ BRASIL. Código Civil e Constituição Federal e legislação complementar: miniobra coletiva de autoria da Editora Saraiva com a colaboração de Luiz Roberto Curia, Livia Céspedes e Juliana Nicoletti. 21. ed.- São Paulo: Saraiva, 2015, p. 173.

${ }^{9}$ Idem, p. 139.
} 


\section{UM CONCEITO ATUAL DE FAMÍLIA: A POLIAFETIVIDADE OU POLIAMOR}

Foi-se o tempo em que o signo família designava apenas aquela composta por pai, mãe e filhos. Apesar de ainda vigente em muitos dicionários, vê-se que tal conceito se modifica muito ao se tomar como base a sociedade atual.

É certo que o mundo está em constante evolução, e, por conseguinte, a sociedade e seus inúmeros eixos. Dentre eles, a família, com suas variadas alterações. Temos que o núcleo familiar brasileiro sofreu grandes mudanças, principalmente, após o advento do Estado Social. Neste sentido, o Estado começou a se interessar mais por tais relações e a partir disso aumentar sua tutela constitucional, mas, na maioria das vezes, não acompanhando a exponencial evolução da sociedade. É neste contexto que a família patriarcal, pautada em valores tradicionais, entra em crise, sendo derrocada pelos valores presentes na Constituição de 1988. A partir de então, a unidade familiar começa a ser matrizada na afetividade, na liberdade e na responsabilidade, e, consolidada na comunhão e na colaboração, conforme explana Paulo Lobos. ${ }^{10}$ Desse modo, o conceito de família composto por tais bases torna-se um direito subjetivo público, oponível ao próprio Estado e à sociedade, e hoje é um princípio universalmente aceito e adotado pela maioria dos países ao redor do mundo.

Conforme dito, tal instituição é fixada pela Declaração Universal dos Direitos do Homem, votada pela ONU (Organização das Nações Unidas) em 10 de dezembro de 1948, assegurando às pessoas humanas o direito de fundar uma família, nos termos do art. 16.3:

A família é o núcleo natural e fundamental da sociedade e tem direito à proteção da sociedade e do Estado. Desse Capítulo I 18 positivo defluem conclusões evidentes: a) família não é só aquela constituída pelo casamento, tendo direito todas as demais entidades familiares socialmente constituídas; b) a família não é célula do Estado (domínio da política), mas da sociedade civil, não podendo o Estado tratá-la como parte sua. ${ }^{11}$

\footnotetext{
${ }^{10}$ LOBO, Paulo. Direito civil: famílias. 4. ed. São Paulo: Saraiva, 2011, p. 17.

${ }^{11}$ Idem, p. 17-18.
} 
Nesse ínterim, tendo em vista a família poliafetiva, para alguns, não se trata de uma evolução com o posterior surgimento de um novo tipo de família, mas sim algo que já se verificava: "Só estamos documentando o que sempre existiu. Não estamos inventando nada.". ${ }^{12}$

A documentação a que se refere o trecho citado diz respeito a termos de um acordo definido oficialmente como "escritura pública declaratória de união estável poliafetiva", que foi o fato responsável por trazer tal "polêmica" à tona.

Segundo o caso, três indivíduos (duas mulheres e um homem) procuraram vários tabeliães que se recusaram a lavrar a tal escritura, até chegar a tabeliã de notas e protestos da cidade de Tupã, Cláudia do Nascimento Domingues: "Quando eles entraram em contato comigo, eu fui averiguar se existia algum impedimento legal e verifiquei que não havia. Eu não poderia me recusar a lavrar a declaração. $O$ tabelião tem a função pública de dar garantia jurídica ao conhecimento de fato". ${ }^{13}$

Segundo Cláudia ${ }^{14}$, tal nova forma de família não afeta o direito das outras pessoas, como também possui as mesmas garantias, em toda sua extensão e igualdade: para a advogada, na prática, o documento deixa claro as vontades das três pessoas, com diversas cláusulas (de pensão, comunhão de bens até planos de saúde e separação). Entretanto, caberá à empresas e aos órgãos públicos aceitarem ou não o trio como "unidade familiar", ficando os tribunais responsáveis por julgarem a validade dos potenciais recursos.

Consoante à tabeliã, os três já viviam em união estável há mais de três anos e queriam declarar isto, então, ela apenas se comprometeu a redigir uma escritura organizando essas declarações de forma pública, para a garantia de seus direitos. ${ }^{15}$ Uma vez que: “...havia um desejo comum

\footnotetext{
${ }^{12}$ DOMINGUES, Cláudia do Nascimento. União Poliafetiva. São Paulo, BBC Brasil, atualizado em 28 de agosto, 2012. Entrevista concedida á Jefferson Puff. Disponível em:< http://www.bbc.com/portuguese/noticias/2012/08/120828_ping_uniao_poliafetiva_jp.shtml>. Acesso em 18/11/2015.

${ }^{13}$ IBDFAM. Instituto Brasileiro de Direito de Família. Escritura reconhece união afetiva a três. Instituto Brasileiro de Direito de Família, 21/08/2012. Disponível em: $<$ http://www.ibdfam.org.br/noticias/4862/novosite>. Acesso em 26/08/2016.

${ }^{14}$ DOMINGUES, Cláudia do Nascimento. União Poliafetiva. São Paulo, BBC Brasil, atualizado em 28 de agosto, 2012. Entrevista concedida á Jefferson Puff. Disponível em: $<$ http://www.bbc.com/portuguese/noticias/2012/08/120828_ping_uniao_poliafetiva_jp.shtml>. Acesso em 18/11/2015.

${ }^{15}$ Ibidem.
} 
entre as partes, se tratava de pessoas capazes, sem envolvimento de nenhum menor e sem litígio". ${ }^{16}$

Abaixo, segue trecho da referida Escritura Pública Declaratória de União Poliafetiva:

Os declarantes, diante da lacuna legal no reconhecimento desse modelo de união afetiva múltipla e simultânea, intentam estabelecer as regras para garantia de seus direitos e deveres, pretendendo vê-las reconhecidas e respeitadas social, econômica e juridicamente, em caso de questionamentos ou litígios surgidos entre si ou com terceiros, tendo por base os princípios constitucionais da liberdade, dignidade e igualdade. ${ }^{17}$

A partir disto, a escritura estabelece os direitos e deveres dos conviventes, um regime patrimonial de comunhão parcial (análogo à comunhão parcial estabelecida nos artigos 1.658 a 1.666 do Código Civil Brasileiro ${ }^{18}$ ), e, por fim, a dissolução da união poliafetiva, bem como os efeitos jurídicos de tal ato.

Também merecem destaque, outros casos de registro de escritura entre casais poliafetivos, ocorridos no Rio de janeiro, pela tabeliã Fernanda de Freitas Leitão, do $15^{\circ}$ Ofício de Notas: o primeiro, uma união entre três mulheres, em outubro de 2015; e outro, de um homem e duas mulheres em $1^{\circ}$ de abril, causando uma imensa repercussão midiática. Nesta última, o objetivo de oficializar a união, segundo os mesmos, foi a regularização de questões previdenciárias e plano de saúde.

Os fundamentos que devem ser levados em conta neste tipo de lavratura, de acordo com a tabeliã, são:

Princípio da afetividade, como novo pilar do Direito de Família. O princípio da dignidade da pessoa humana, da personalidade, da autonomia da vontade, da não-discriminação e, por fim, o silêncio normativo,

\footnotetext{
${ }^{16}$ IBDFAM. Instituto Brasileiro de Direito de Família. Escritura reconhece união afetiva a três. 21/08/2012. Disponível em: <http://www.ibdfam.org.br/noticias/4862/novosite>. Acesso em $26 / 08 / 2016$.

${ }^{17}$ Ibidem.

${ }^{18}$ BRASIL. Código Civil e Constituição Federal e legislação complementar: miniobra coletiva de autoria da Editora Saraiva com a colaboração de Luiz Roberto Curia, Livia Céspedes e Juliana Nicoletti. -21. ed.- São Paulo: Saraiva, 2015, p. 168.
} 
pois no âmbito do Direito Privado, tudo o que não é proibido é permitido. ${ }^{19}$

Tais fundamentos convergem para uma compreensão de família como algo plural e aberto nos dias hoje.

Em contraste, está a oposição da Corregedoria Geral da Justiça do Tribunal de Justiça do Estado do Rio de Janeiro (CGJ/RJ), a qual foi imediata, emitindo uma nota, na qual se proclama: "os efeitos de uma escritura declaratória de união poliafetiva não são equiparados aos efeitos do registro de casamento ou da escritura de união estável" ${ }^{20}$, e ainda que tais uniões não eram reconhecidas no ordenamento brasileiro, não sendo os demais cartórios obrigados a lavrarem escrituras semelhantes.

Indo em sentido oposto, rebate o advogado Marcos Alves da Silva, membro do Instituto Brasileiro de Direito de Família (IBDFAM):

O problema é que somos um País cartorial e temos ainda o casamento como critério e régua para medir uma conjugalidade sem matrimônio. Digo de forma categórica: não existe escritura pública que constitua união estável. O que constitui uma união estável não é o seu registro em cartório, mas os pré-requisitos exigidos por lei, quais sejam, o fato social, ostensibilidade ou publicidade, durabilidade, continuidade e um elemento teleológico que é a intenção de constituir família. Pois bem, se duas pessoas comparecem diante de um Cartório de Notas e fazem, por escritura pública, um 'pacto de união estável', mas, nunca venham a estabelecer entre si qualquer união, em verdade, a escritura por si só não produz efeito jurídico algum. Trata-se de uma declaração inócua. Isto porque, nos termos do Código Civil brasileiro, é o fato social e não a formalização de uma escritura que tem o condão de fazer surgir a união estável. ${ }^{21}$

\footnotetext{
${ }^{19}$ IBDFAM. Rio de Janeiro registra mais uma união poliafetiva. Instituto Brasileiro de Direito de Família, 06/04/2016. Disponívelem: < http://www.ibdfam.org.br/noticias/5961/Rio+de+Janeiro+registra+mais+uma+uni\%C3\%A3o+poliafetiva>. Acesso em 29/08/2016.

${ }^{20}$ IBDFAM. Instituto Brasileiro de Direito de Família. União poliafetiva: escritura é necessária? 20/04/2016. Disponível em:<http://www.ibdfam.org.br/noticias/5970>. Acesso em 26/08/2016.

${ }^{21}$ Ibidem.
} 
O advogado complementa dizendo que a união estável não precisa de cartório e que a escritura pública é plenamente dispensável: "O contrato (pacto), nos termos da lei, pode ser por instrumento particular, ou, como já disse, pode nem sequer existir" ${ }^{22}$, ressalta o advogado. Sendo que a escritura pública só confere a vantagem da autenticidade, da fé-pública, não sendo o contrato que constitui união estável. ${ }^{23}$ Mas que, no entanto, reitera que os efeitos jurídicos da união poliafetiva dependerão da aprovação do Poder Judiciário, quando for provocado.

Segundo Alves, não existe diferença "ontológica" ou de natureza jurídica de contrato ou pacto de união estável entre duas, três ou seis pessoas. Ademais, o advogado também entende que o notário não pode negarse a fazer a escritura de união poliafetiva: "Não concebo a possibilidade de um notário negar-se a reduzir a termo, por escritura pública, uma declaração feita por uma pessoa sobre um determinado fato" ${ }^{24}$, diz.

Além disto, "o contrato constitui mera faculdade estabelecida pela lei, para que, por meio dele, os companheiros possam definir os efeitos patrimoniais da união entre eles estabelecida, conforme dispõe o artigo 1.725 do Código Civil." ${ }^{25}$ O qual, a título de esclarecimento, segue abaixo: "Na união estável, salvo contrato escrito entre os companheiros, aplica-se às relações patrimoniais, no que couber, o regime da comunhão parcial de bens."

Desse modo, compreende-se que a declaração de união estável tem, basicamente, três finalidades: dar certeza quanto ao tempo de vigência da união estável, definir os efeitos patrimoniais e promover segurança jurídica. Com a união oficializada, os indivíduos passam a ter prerrogativas, principalmente no caso de separação. "Se tivessem filhos, eles poderiam combinar que todos seriam responsáveis pelos custos da criação. Em uma situação de doença, eles poderiam se visitar e se apresentar como membros da mesma família e, em caso de separação, facilita a organização da divisão de bens e patrimônios"26, esclarece Domingues.

\footnotetext{
${ }^{22}$ IBDFAM. Instituto Brasileiro de Direito de Família. União poliafetiva: escritura é necessária? 20/04/2016. Disponível em:<http://www.ibdfam.org.br/noticias/5970>. Acesso em 26/08/2016.

${ }^{23}$ IBDFAM. Rio de Janeiro registra mais uma união poliafetiva. Instituto Brasileiro de Direito de Família, 06/04/2016. Disponível em:< http://www.ibdfam.org.br/noticias/5961/Rio+de+Janeiro+registra+mais+uma+uni\%C3\%A3o+poliafetiva>. Acesso em 29/08/2016.

${ }^{24}$ Ibidem.

${ }^{25}$ Ibidem.

${ }^{26}$ DOMINGUES, Cláudia do Nascimento. União Poliafetiva. São Paulo, BBC Brasil, atualizado em 28 de agosto, 2012. Entrevista concedida á Jefferson Puff. Disponível em: $<$ http://www.bbc.com/portuguese/noticias/2012/08/120828_ping_uniao_poliafetiva_jp.shtml>. Acesso em 18/11/2015.
} 
Por fim, como não existe na Constituição brasileira nenhuma referência sobre a impossibilidade de uma união estável entre três pessoas, os casos não podem ser entendidos como um desvio da norma nacional.

Todavia, deve-se levar em conta que tais escrituras são meramente declaratórias. Apesar disto, se a situação vier a ser amparada pelo ordenamento, as pessoas passarão a ter seus direitos garantidos.

Tal tema, embora deveras hodierno, pode ser remetido à teoria do "amor livre", surgida no século XIX, no seio do movimento anarquista, em conjunto com a rejeição da interferência do Estado e da igreja na vida e nas relações pessoais. Seus seguidores acreditam que a igreja e o Estado não têm o direito de definir o que deve ou não ser considerado um relacionamento amoroso e em face disto, defendiam a prática todo tipo de relação amorosa - inclusive a monogâmica - não atrelada a quaisquer registros formais, posse, controle ou nome. Além do mais, no século XX, alguns proponentes do amor livre alargaram a crítica à instituição do casamento argumentando que este encoraja a dependência psicológica.

Dentro dessa perspectiva, observa-se a mais autêntica expressão da liberdade. Nesses relacionamentos, geralmente, os integrantes são bissexuais, tendo relações dentro de um mesmo núcleo e/ou fora dele com outros parceiros tanto com parceiros do sexo oposto como do mesmo sexo. Aqui, predomina a compersão, tipificada como sendo o sentimento de alegria ou de felicidade de uma pessoa ao ver seu parceiro amoroso feliz com outra pessoa, ou seja, uma nítida ausência ou superação do ciúme entre parceiros amorosos.

Por fim, em relação a como este conceito se dá em outros lugares do mundo, Cláudia explana:

A primeira ideia que vem à cabeça é das famílias patriarcais em alguns países do mundo árabe e da África, com famílias de um homem e muitas mulheres. Os tradicionais haréns, coisas do tipo. Mas há sociedades matriarcais, na região do Himalaia, por exemplo, onde a mulher é que tem diversos maridos, e todos se esforçam para ser o favorito, enquanto na Índia, em muitas famílias, as mulheres brigam para serem a favorita do marido. Não tenho dados oficiais ainda, mas já encontrei a incidência comprovada de famílias poliafetivas em lugares como os Estados Unidos, a França e a Grã-Bretanha, além de outros países europeus. Até o momento, no entanto, não 
identifiquei registros de escrituras públicas semelhantes à lavrada aqui nem na Europa e nem na América Latina, há apenas contratos privados entre os membros dessas famílias. ${ }^{27}$

\section{A INTERFERÊNCIA ESTATAL NA VIDA PRIVADA E SEUS LIMITES}

\subsection{A RELAÇÃO COM A MONOGAMIA;}

Como acima mencionado, em 21 de agosto de 2012, data na qual foi lavrada a escritura de união estável poliafetiva entre um homem e duas mulheres na cidade de Tupã/SP, pela vanguardista tabeliã Maria Berenice Dias, a qual interpreta tal ato com base nos princípios constitucionais da igualdade, da dignidade da pessoa humana e da liberdade para justificar a juridicidade de tal escritura, há um marco fundamental para o tema dentro do direito de família, uma vez que tal ato recai em uma consequente reafirmação da juricidade do feito, incorrendo na ausência de proibição legal, segundo a advogada.

Para a vice-presidente do Instituto Brasileiro de Família (IBDFAM), Maria Berenice Dias, não há problemas em assegurar direitos e obrigações a uma relação contínua e duradoura só pelo fato de conter três indivíduos:

O princípio da monogamia não está na constituição, é um viés cultural. $\mathrm{O}$ código civil proíbe apenas casamento entre pessoas casadas, o que não é o caso. Essas pessoas trabalham, contribuem e, por isso, devem ter seus direitos garantidos. A justiça não pode chancelar a injustiça. ${ }^{28}$

\footnotetext{
${ }^{27}$ DOMINGUES, Cláudia do Nascimento. União Poliafetiva. São Paulo, BBC Brasil, atualizado em 28 de agosto, 2012. Entrevista concedida á Jefferson Puff. Disponível em:< http://www.bbc.com/portuguese/noticias/2012/08/120828_ping_uniao_poliafetiva_jp.shtml>. Acesso em 18/11/2015.

${ }^{28}$ IBDFAM. Instituto Brasileiro de Direito de Família. Escritura reconhece união afetiva a três. Instituto Brasileiro de Direito de Família, 21/08/2012. Disponível em: $<$ http://www.ibdfam.org.br/noticias/4862/novosite>. Acesso em 26/08/2016.
} 
Ou seja, a monogamia é princípio que sequer consta por escrito na Carta brasileira, mas, por outro lado, é defendido pela sociedade e pelos tribunais em geral, devido a uma consagração cultural. No entanto, isto está se modificando a passos lentos e evidenciando que tal modelo único de constituição de família está indo na contramão da evolução e dinâmica social, bem como do direito à felicidade e da dignidade da pessoa humana. $\mathrm{O}$ que é confirmado pelo artigo 235 do Código Penal, juntamente com artigo $5^{\circ}$ da Constituição Federal, os quais se seguem:

Art. 235 - Contrair alguém, sendo casado, novo casamento: Pena - reclusão, de dois a seis anos. $\S 1^{\circ}$ Aquele que, não sendo casado, contrai casamento com pessoa casada, conhecendo essa circunstância, é punido com reclusão ou detenção, de um a três anos. $\S 2^{\circ}$ - Anulado por qualquer motivo o primeiro casamento, ou o outro por motivo que não a bigamia, considera-se inexistente o crime.

Art. $5^{\circ}$ Todos são iguais perante a lei, sem distinção de qualquer natureza, garantindo-se aos brasileiros e aos estrangeiros residentes no País a inviolabilidade do direito à vida, à liberdade, à igualdade, à segurança e à propriedade, nos termos seguintes...".

Desse modo, verifica-se que a lei restringe a bigamia somente ao casamento civil e não à união estável. É importante destacar que a bigamia ocorre quando uma pessoa casada contrai outro matrimônio, o que se distancia da questão de uma possível institucionalização da bigamia devido à união poliafetiva, já que esta, na época vigente, vem sendo apenas declarada através de certidão de união estável.

Nesse ínterim, também cabe explanar que a relação poliafetiva não se trata de uma relação poligâmica. Esta é uma forma de relacionamento entre duas ou mais pessoas, podendo ser a poliginia (quando o homem tem mais de uma mulher ou companheira) ou poliandria (quando a mulher tem mais de um marido ou companheiro), mas nas quais se dá a formação de vários núcleos familiares, enquanto no poliamor temos somente um único, com noção de unidade.

\subsection{A RELAÇÃO COM A LIBERDADE DE ESCOLHA;}


Para alguns, o estabelecimento da união estável nas famílias poliafetivas é considerado um "estelionato jurídico", tendo em vista que o seu reconhecimento violaria a dignidade humana, além de destruir famílias. Deve-se observar que tal informação:

(i) implica em uma descabida naturalização da monogamia como "única" forma "aceitável/digna/válida/viável" de família conjugal;

(ii) desconsidera que pelo menos para algumas pessoas a poliafetividade é capaz de trazer satisfação/realização e felicidade a seus integrantes;

(iii) ignora as diversas mazelas e opressões praticadas contra a mulher em famílias conjugais monogâmicas/monoafetivas ao longo da história (já que claramente presume que a monogamia seria o único paradigma válido/digno/aceitável/viável de relacionamento conjugal $[\ldots] .{ }^{29}$

Acima de tudo, desde que não haja opressão entre seus integrantes ou cause danos a terceiros, não cabe ao Estado decidir com quem e com quantas pessoas, os indivíduos adultos devam se relacionar, formar laços e famílias conjugais.

Desse modo, não se deve deixar um mero moralismo estatal exercer tamanha influência na vida das pessoas. Uma vez que: "Presentes os requisitos da afetividade, publicidade, continuidade, durabilidade e a intenção de constituição de família, não importa a estrutura que tome a família". ${ }^{30}$ Sendo cabível ao Estado somente a interferência no âmbito familiar para assegurar a liberdade e o respeito a seus membros, conforme disposto no artigo 1513 do Código Civil: "É defeso a qualquer pessoa, de direito público ou privado, interferir na comunhão de vida instituída pela família."

Ademais, no referente à escritura de união estável, os cartórios exercem função delegada do Estado. Desse modo, não há cabimento de um notário se recusar a realizar tal ato. Além do que, isto implicaria em uma grande intromissão na intimidade e privacidade das pessoas, inibindo que

\footnotetext{
${ }^{29}$ VECCHIATTI, Paulo Roberto Iotti. União Estável Poliafetiva: Breves Considerações acerca de sua constitucionalidade. Disponívelem:< http://www.arpensp.org.br/?pG=X19leGliZV9ub3RpY2lhcw==\&in=MTcwODk=\&filtro=2)>; acesso em 27 de outubro de 2015.

${ }^{30}$ IBDFAM. Instituto Brasileiro de Direito de Família. Rio de Janeiro registra mais uma união poliafetiva. Instituto Brasileiro de Direito de Família, 06/04/2016. Disponível em: <http://www.ibdfam.org.br/noticias/5961/Rio+de+Janeiro+registra+mais+uma+uni\%C3\%A3o+poliafetiva>. Acesso em $29 / 08 / 2016$.
} 
elas declarem o que bem lhes aprouver e o façam por meio de instrumento que empreste fé-pública ao que querem deixar registrado. "Agora, a validade e a eficácia das declarações vertidas em Escritura pública sempre poderão ser submetidas ao escrutínio do Poder Judiciário", reflete Marcos Alves. ${ }^{31}$

O professor ressalta que "o nosso direito não impede o exercício da nossa sexualidade ou das nossas experiências de interação subjetiva da forma como nós queiramos experimentá-las". ${ }^{32}$ Mas, ainda assim, a formalização, através de escrituras, é importante para que as partes possam obter uma eficácia na garantia de seus direitos.

Enfim, cabe dizer, que nosso ordenamento jurídico não estava preparado para esse novo formato de entidade familiar, nem a Constituição da República, tampouco o Código Civil. "Contudo, dizer que o nosso ordenamento jurídico não permite esse tipo de união é imaginar que o legislador pátrio pensou nessa situação e a proibiu, o que, a meu ver, não aconteceu" ${ }^{33}$. Uma vez que não cabe ao Estado tamanha interferência na vida privada das pessoas, a ponto de tomar-lhes a liberdade de se relacionar com pessoas de sua preferência. Temos que respeitar a natureza privada dos relacionamentos e aprender a viver nessa sociedade plural, reconhecendo os diferentes desejos e afetos.

\section{COMO A LEI E A JUSTIÇA AGEM EM TAIS CASOS:}

\subsection{O DILEMA ENTRE O CASAMENTO E A UNIÃO ESTÁVEL;}

Dando continuidade, assevera-se que existem juristas que negam a juridicidade de tal escritura, por considerá-la como contrária à Constituição, uma vez que a família brasileira teria "natureza monogâmica":

Art 226. [...]

\footnotetext{
${ }^{31}$ IBDFAM. Instituto Brasileiro de Direito de Família. União poliafetiva: escritura é necessária? 20/04/2016. Disponível em:<http://www.ibdfam.org.br/noticias/5970>. Acesso em 26/08/2016.

32 Ibidem.

${ }^{33}$ IBDFAM. Instituto Brasileiro de Direito de Família. União poliafetiva: escritura é necessária? 20/04/2016. Disponível em:<http://www.ibdfam.org.br/noticias/5970>. Acesso em 26/08/2016.
} 
$\S 3^{\circ}$ Para efeito da proteção do Estado, é reconhecida a união estável entre o homem e a mulher como entidade familiar, devendo a lei facilitar sua conversão em casamento. [...]

$\S 5^{\circ}$ Os direitos e deveres referentes à sociedade conjugal são exercidos igualmente pelo homem e pela mulher.

Um dos argumentos utilizados é o de que, o texto normativo relativo ao casamento civil e à união estável, conforme trecho acima exposto utilizou a expressão "entre o homem e a mulher". Dessa maneira, isto teria limitado a família conjugal, a qual é protegida pelo ordenamento jurídico, somente à união entre duas pessoas, donde não seria possível reconhecer uma união estável entre mais de duas pessoas, pela inexistência de flexão plural dos substantivos.

Contudo, esse é um argumento pode ser considerado muito fraco, pois tomando por base os princípios de Direito Civil Clássico, tem-se que caso um texto normativo regulamente um fato sem nada dispor sobre outro, isto se configura como lacuna normativa colmatável por interpretação extensiva ou analógica se as situações sejam idênticas ou, se diferentes, sejam idênticas no essencial, respectivamente. E não uma "proibição implícita". Além do conceito norma geral negativa, segundo a qual, tudo o que não estiver juridicamente proibido está juridicamente permitido. Logo, o texto não teria negado proteção à união estável entre mais de duas pessoas.

Ademais, o art. 226 da Constituição Federal:

[...] é meramente exemplificativo, não taxativo, de sorte ser juridicamente possível o reconhecimento de entidades familiares autônomas, além daquelas previstas nos parágrafos do dito dispositivo constitucional, o que a doutrina contemporânea isto reconhece com relativa tranquilidade. ${ }^{34}$

Tal artigo, o qual segue abaixo, ao afirmar que a família merece especial proteção do Estado e não mais que a família é constituída pelo casamento, dá o significado que toda família merece proteção, ou seja, todo agrupamento humano que se encaixe no conceito ontológico de família e

${ }^{34}$ IBDFAM. Instituto Brasileiro de Direito de Família. União poliafetiva: escritura é necessária? 20/04/2016. Disponível em:<http://www.ibdfam.org.br/noticias/5970>. Acesso em 26/08/2016. 
não uma família meramente matrimonializada. Consagrando, assim, a pluralidade das entidades familiares:

Art. 226. A família, base da sociedade, tem especial proteção do Estado.

$\S 1^{\circ} \mathrm{O}$ casamento é civil e gratuita a celebração.

$\S 2^{\circ} \mathrm{O}$ casamento religioso tem efeito civil, nos termos da lei.

$\S 3^{\circ}$ Para efeito da proteção do Estado, é reconhecida a união estável entre o homem e a mulher como entidade familiar, devendo a lei facilitar sua conversão em casamento.

$\S 4^{\circ}$ Entende-se, também, como entidade familiar a comunidade formada por qualquer dos pais e seus descendentes.

$\S 5^{\circ}$ São indisponíveis as terras devolutas ou arrecadadas pelos Estados, por ações discriminatórias, necessárias à proteção dos ecossistemas naturais.

$\S 6^{\circ}$ As usinas que operem com reator nuclear deverão ter sua localização definida em lei federal, sem o que não poderão ser instaladas.

Ademais, em relação ao casamento, ressalta a tabeliã Fernanda que não há qualquer tipo de impedimento: "Além disso, a união deve ser pública, contínua e duradoura, com objetivo de formar família, e as partes devem ser maiores e capazes, não havendo nenhum dos impedimentos constantes do art. 1.521, do Código Civil". ${ }^{35} \mathrm{O}$ qual se encontra na íntegra a seguir:

Não podem casar: I - os ascendentes com os descendentes, seja o parentesco natural ou civil; II - os afins em linha reta; III - o adotante com quem foi cônjuge do adotado e o adotado com quem o foi do adotante; IV - os irmãos, unilaterais ou bilaterais, e demais colaterais, até o terceiro grau inclusive; V - o adotado com o filho do adotante; VI - as pessoas casadas; VII

\footnotetext{
${ }^{35}$ IBDFAM. Rio de Janeiro registra mais uma união poliafetiva. Instituto Brasileiro de Direito de Família, 06/04/2016. Disponívelem:< http://www.ibdfam.org.br/noticias/5961/Rio+de+Janeiro+registra+mais+uma+uni\%C3\%A3o+poliafetiva>. Acesso em 29/08/2016.
} 
- o cônjuge sobrevivente com o condenado por homicídio ou tentativa de homicídio contra o seu consorte.

Nesse mesmo sentido, nota-se que este é facilitado, conforme art. 1.726: "A união estável poderá converter-se em casamento, mediante pedido dos companheiros ao juiz e assento no Registro Civil", juntamente com o art. 1723:

Art. 1.723. É reconhecida como entidade familiar a união estável entre o homem e a mulher, configurada na convivência pública, contínua e duradoura e estabelecida com o objetivo de constituição de família. § 1o A união estável não se constituirá se ocorrerem os impedimentos do art. 1.521; não se aplicando a incidência do inciso VI no caso de a pessoa casada se achar separada de fato ou judicialmente. $\S 20$ As causas suspensivas do art. 1.523 não impedirão a caracterização da união estável.

Em suma, o casamento cria um vínculo matrimonial entre as pessoas através da lei, gerando direitos e obrigações. Durante muitos anos, devido à cultura religiosa brasileira, era o único tipo de relação existente possível no país. Fora do casamento, existia a família ilegítima, a chamada concubinagem, a qual, a princípio, não tinha direito algum, mas, que aos poucos foram sendo conquistados, desde 1912. Com a Constituição de 1988, como já mencionado, o conceito de família se altera, estabelecendo uma nova visão, na qual o vínculo legal matrimonial não era mais a exclusiva forma de constituição de família. Tal liame passa a ser baseado na afetividade. E, com isso, dá-se o surgimento da família afetiva, que nada mais é do que a união estável. Isto é, uma união entre duas pessoas que formam um vínculo familiar através do afeto. A partir disso, tal conceito se expande para todos os setores, tendo a afeição na família como um todo e não só com o casamento. Desse modo, flexibiliza o conceito familiar, no qual não é mais necessário o casamento, para ser considerado como tal.

\subsection{A TÉCNICA DA PONDERAÇÃO;}

De um lado, estão os seguintes princípios e normas: a proibição da discriminação (homem/mulher, orientação sexual); direitos 
fundamentais do indivíduo; autonomia da vontade; proibição do preconceito; silêncio normativo; princípio da dignidade da pessoa humana; direito à busca da felicidade; direito à liberdade sexual; interpretação não reducionista do conceito de família e interpretação do artigo 1.723, do Código Civil, conforme a Constituição da República.

De outro, está a impossibilidade da "existência" famílias poliafetivas, uma vez que as mesmas não estão enquadradas e tipificados como família.

Destarte, o debate recai sobre a possibilidade ou não do reconhecimento da união poliafetiva como um novo modelo de união estável e se tais relações merecem o mesmo respeito e reconhecimento que a sociedade outorga às demais uniões, ou seja, a aprovação do Estado.

Cabe aqui, portanto, a ponderação de valores, através da proporcionalidade de princípios, baseada na conformação-adequação de meios, necessidade-exigibilidade e da proporcionalidade em sentido estrito.

Nesse aspecto, elucida-se que:

A ponderação, como veremos a seguir, subdivide-se nos campos da justificação interna e justificação externa. A justificação interna, em poucas linhas, seria a própria ponderação. Já a justificação externa seria responsável, através de uma teoria da argumentação, por sustentar aquela resposta que foi encontrada através de um procedimento racional. ${ }^{36}$

Em suma, deve-se ter em mente que ponderar não é utilizar o bom senso e nem julgar de acordo com sua consciência, fatos muito recorrentes nos tribunais brasileiros, mas sim, basear-se na racionalidade, proporcionalidade e adequação. ${ }^{37}$

Por fim, opina Domingues sobre um possível desfecho, caso uma ação chegasse ao Supremo:

Na minha experiência, tenho visto que, em casos parecidos, em primeira instância, a solicitação costuma ser negada, e, com recursos subsequentes, chega-se ao Supremo Tribunal Federal, que julgará a ação com um

\footnotetext{
${ }^{36}$ MAIA, Isabela Rebouças; CARNEIRO, Wálber Araújo. O que é isto? Ponderação de Princípios. XII SEPA - Seminário Estudantil de Produção Acadêmica, UNIFACS, 2013, p.14.

${ }^{37}$ Idem, p. 18.
} 
olhar constitucional. Foi o que aconteceu com as famílias homoafetivas. Mas é claro que a corte pode aprovar ou não a ação. ${ }^{38}$

O Supremo Tribunal Federal reafirmou essa compreensão, ao julgar a ADIn 4.277 e ADPF 132, determinando que a hermenêutica do art. 1.723 do Código Civil deveria ser realizada por meio da leitura conforme a constituição, de modo a atribuir às uniões homoafetivas os mesmos efeitos e consequências da união estável heterossexual. Desse modo, não é somente a leitura do caput do art. 1.723 que deve ser realizada conforme a Constituição, mas, de todas as situações existenciais que podem configurar conjugalidade, mesmo que não haja previsão legal expressa daquele "novo" modelo de família. Em outras palavras, depois da Constituição de 1988, as famílias existem, independentemente, de previsão expressa em Lei, tendo em vista a fundamental proporcionalidade entre a igualdade material e a dignidade da pessoa humana; entre afetividade e liberdade individual, uma vez que afeto não escolhe sexo.

\subsection{O POSSÍVEL PRECONCEITO FRENTE À SOCIEDADE ATUAL.}

Assim como a poliafetividade em si, os casos surgidos na mídia, como o de Tupã e do Rio de Janeiro, deverão encontrar dificuldades e preconceitos. No entanto, a advogada Cláudia espera que o caso abra precedentes para vários outros modelos de família, que podem incluir dois homens e uma mulher, três homens, duas mulheres e dois homens. "Há várias possibilidades" 39 , disse.

Ademais, segundo a mesma, a questão gira em torno do conceito de lealdade e não de fidelidade. Este último está enraizado no Brasil, ligado ao casamento, a um sentimento de pertencimento. Segundo explica, esta é apenas uma das formas de ver a vida, que não está errada, mas existem

\footnotetext{
${ }^{38}$ DOMINGUES, Cláudia do Nascimento. União Poliafetiva. São Paulo, BBC Brasil, atualizado em 28 de agosto, 2012. Entrevista concedida á Jefferson Puff. Disponível em: $<$ http://www.bbc.com/portuguese/noticias/2012/08/120828_ping_uniao_poliafetiva_jp.shtml>. Acesso em 18/11/2015.

${ }^{39}$ Ibidem.
} 
muitas outras e termina: "Países como a Dinamarca, por exemplo, aprovaram a união homossexual 30 anos atrás". ${ }^{40}$

Vivemos ainda em uma sociedade muito preconceituosa, limitada. Dentro disso, tal tipo de família é vista como uma afronta a valores, historicamente construídos. Ademais, os críticos sexualizam a questão, como uma tentativa de decidir quem deve fazer sexo com quem.

Indo além, no tocante aos filhos, Cláudia argumenta que o reconhecimento de filhos pelas pessoas pertencentes às famílias poliafetivas deverá ser de luta, recorrendo a Justiça, assim como foi para os casais homoafetivos:

Quando procurarem um oficial de registro civil, com o documento trazido pelo médico apenas constando o nome dos pais biológicos, terão o pedido rejeitado. Se eles quiserem, com o auxílio de um advogado, discutir a possibilidade de incluir os três, ou quatro, ou cinco nomes como pais, terão que argumentar que constituem uma família, porque de fato serão pais afetivos da criança, em uma ação judicial. Aí entra o juiz para dizer se reconhece ou não a paternidade e maternidade conjunta. Os filhos foram incluídos no texto não como parte da relação familiar, mas como uma previsão de responsabilidade conjunta. ${ }^{41}$

Não há legislação que trate do assunto. A aceitação envolve a maturação do Direito. "Nesse caso, foi preciso atribuir o direito a partir de um fato concreto". ${ }^{42}$ É o que mais deve ocorrer, em tempos futuros, uma vez que vivemos em uma sociedade em (re)construção, na qual deve haver o reconhecimento de todos os relacionamentos que fazem parte dela.

Embora, para Marcos Alves, o país vivencie um momento de "recrudescimento" de posturas conservadoras e autoritárias, "temperadas de um inegável fundamentalismo religioso", mas, que, no entanto, não devem predominar.

\footnotetext{
${ }^{40}$ DOMINGUES, Cláudia do Nascimento. União Poliafetiva. São Paulo, BBC Brasil, atualizado em 28 de agosto, 2012. Entrevista concedida á Jefferson Puff. Disponível em: $<$ http://www.bbc.com/portuguese/noticias/2012/08/120828_ping_uniao_poliafetiva_jp.shtml>. Acesso em 18/11/2015.

${ }^{41}$ Ibidem.

${ }^{42}$ IBDFAM. Instituto Brasileiro de Direito de Família. Escritura reconhece união afetiva a três. Instituto Brasileiro de Direito de Família, 21/08/2012. Disponível em:<http://www.ibdfam.org.br/noticias/4862/novosite>. Acesso em 26/08/2016.
} 
Há nítida mobilização de setores no parlamento e fora dele que é autêntica expressão de retrógrados preconceitos, de manifestações de homofobia, misoginia, etc. Esses setores sentem-se, nesse momento, fortalecidos em razão de que seus representantes têm alcançado certo protagonismo político", diz. Contudo, segundo ele, o Poder Judiciário tende a atuar de forma mais cautelosa e técnica, "recusando, ao menos em tese, o contágio das pressões conjunturais da política. Entendo que por esse caminho deve enveredar o CNJ".

No mesmo sentido, apesar de nem todas as relações familiares terem merecido a compreensão judicial e o enquadramento legal, o fato é que a Constituição Federal proíbe qualquer discriminação entre as pessoas do mesmo sexo e protege a pluralidade das entidades familiares, embora só reconheça três de suas diferentes modalidades. Desse modo, ela precisa acompanhar esta redefinição, concluindo que não existe um único modelo dominante de família. O que só será possível com o reconhecimento social, retirando tais famílias da invisibilidade jurídica, situadas da marginalização da esfera casamento civil tradicional e consolidando todas as formas de liberdade e igualdade, uma vez que se vive em um Estado laico, plural e democrático e o amor por si só já é livre.

\section{CONSIDERAÇÕES FINAIS: UM NOVO TIPO DE FAMÍLIA QUE SE INSERE NO ORDENAMENTO E NA REALIDADE BRASILEIRA?}

A expressão "uniões poliafetivas", a qual designa um novo modelo de configuração amorosa e familiar, formado a partir da união de mais de dois indivíduos, ou seja, distante da forma convencional do "marido e mulher", como visto ao longo do trabalho, é ainda bastante controversa, dividindo opiniões entre os juristas acerca de tal questão, tendo em vista a extrema atualidade do tema, e, por conseguinte, a ausência de uma legislação específica que o regule e o torne homogêneo quanto às decisões judiciais na prática. Desse modo, tal artigo, teve como objetivo enfrentar a temática das "novas" uniões diante do ordenamento jurídico interno, levando-se em consideração, especialmente e principalmente, aspectos relacionados à interferência estatal na vida privada dos indivíduos e o reconhecimento de famílias poliafetivas como uniões estáveis, o que pode levar à constituição do casamento, uma vez que o ordenamento brasileiro facilita 
a conversão da união estável em casamento, por meio do art. $226, \S 3^{\circ}$, da Constituição Federal.

E conforme exposto, a questão ganhou especial destaque depois que a cartorária Cláudia do Nascimento Domingues, da cidade de Tupã, interior de São Paulo, lavrou uma escritura para "regularizar" a situação entre um homem e duas mulheres que já viviam juntos há três anos na mesma casa. Muito se discute acerca dos efeitos da referida escritura, e ainda sobre os critérios judiciais que envolvem as mencionadas uniões. Entretanto, o cerne da questão reside basicamente na dicotomia entre reconhecer essas uniões como instituição familiar e assim considerá-las enquanto uma ampliação do conceito de família em respeito à liberdade de escolha, bem como os limites envolvendo a atuação estatal atual, levando em consideração seu papel como norteador das decisões sobre Direito de Família ou, negar-lhes reconhecimento, tendo em vista, principalmente, o fundamento de ofensa aos padrões monogâmicos da sociedade ocidental e violação a normas do direito interno.

Além disso, fato de bastante discussão é o preconceito e a discriminação social que podem vir a sofrer tais novas formas de família, ao se levar em conta a não proteção estatal no que tange à legislação. Desse modo, o que se tem é a técnica da ponderação, pautada na proporcionalidade, na necessidade e na adequação, buscando a igualdade material, a consagração de liberdades positivadas, a valorização dos direitos fundamentais da personalidade, da liberdade, da igualdade, e, acima de tudo, da dignidade da pessoa humana além dos atuais mandamentos de acesso à justiça de modo inclusivo a todas as minorias sociais, uma vez que a poliafetividade ou poliamor é uma realidade que não pode ser refutada, devendo ser dever do Direito adaptar-se às constantes mudanças verificadas na dinâmica sociedade brasileira, no que tange à necessidade da criação de leis específicas para essa parcela da sociedade, para que, assim, haja uma maior aceitação, compreensão e inclusão social, por força do princípio da pluralidade de entidades familiares e da ausência de motivação lógico-racional que justifique a negativa de reconhecimento, uma vez que, consoante afirmado pelo Ministro no julgamento da ADPF 132 e da ADI 4.277:

"O que faz uma família é, sobretudo, o amor".

\section{REFERÊNCIAS BIBLIOGRÁFICAS}


BRASIL. Código Civil e Constituição Federal e legislação complementar: miniobra coletiva de autoria da Editora Saraiva com a colaboração de Luiz Roberto Curia, Livia Céspedes e Juliana Nicoletti. -21. ed.- São Paulo: Saraiva, 2015, p. 173.

BRASIL. Código Penal. [colaboração de Antonio Luiz de Toledo Pinto e Márcia Cristina Vaz dos Santos Windt]. São Paulo: Saraiva, 1999.

BURGUIERI, André. História da família /sob a direção de André Burguiere...[et.al.] ; prefácio de Claude Levi-Strauss; tradução : Maria da Assunção Santos. - Lisboa: Terramar, 1996-1999. 4 v.

CAPPELLETTI, Mauro; Garth, Bryant, apud MARTINS, Daniela Dias Graciotto. In: OLIVEIRA, Flávio Luis de; SIQUEIRA, Dirceu Pereira (Org.). Acesso à justiça: uma perspectiva da democratização da administração da justiça nas dimensões social, política e econômica. Birigui: Boreal, 2012.

BRASIL. Constituição da República Federativa do Brasil de 1988. Brasília, DF, Senado, 1988. Disponíel em: <http://www.planalto.gov.br/ccivil_03/constituicao/constituicaocompilado.htm>. Acesso em 26/08/2016.

DIAS, Maria Berenice, 1948. Manual de Direito das Famílias/ Porto Alegre: Livraria do Advogado, 2005.

DOMINGUES, Cláudia do Nascimento. União Poliafetiva. São Paulo, BBC Brasil, atualizado em 28 de agosto, 2012. Entrevista concedida á Jefferson Puff. Disponível em:< http://www.bbc.com/portuguese/noticias/2012/08/120828_ping_uniao_poliafetiva_jp.shtml>. Acesso em $18 / 11 / 2015$..

GONÇALVES, Carlos Roberto. Direito Civil Brasileiro: Direito de Família-Vol 6. São Paulo: Saraiva 2014.

IBDFAM/Instituto Brasileiro de Direito de Família. CNJ recomenda aos cartórios que não façam escrituras de uniões poliafetivas. 04/05/2016. Disponível em: $<\quad$ http://ibdfam.org.br/noticias/5986/-CNJ+recomenda+aos+cart\%C3\%B3rios+que+n\%C3\% A3o+fa\%-C3\%A-7am+escrituras+de+uni\%C3\%B5es+poliafetivas>; acesso em 25 de agosto de 2016, ás 23:45.

IBDFAM/Instituto Brasileiro de Direito de Família. Entrevista com o jurista Rolf Madaleno: união a três - repercussões jurídicas. 29/08/2012. Disponível em:< http://www.ibdfam.org.br/noticias/4870/Entrevista+com+o+jurista+Rolf+Madaleno $\% 3 \mathrm{~A}+$ uni $\% \mathrm{C} 3 \% \mathrm{~A} 3 \mathrm{o}+\mathrm{a}+\mathrm{tr} \% \mathrm{C} 3 \% \mathrm{AAs}+\% \mathrm{E} 2 \% 80 \% 93+$ repercuss $\%$ C3\%B5es+jur\%C3\%ADdicas+>; acesso em 03 de setembro de 2016, ás $13: 21$.

IBDFAM/ Instituto Brasileiro de Direito de Família. Escritura reconhece união afetiva a três. 21/08/2012. Disponível em: $<$ http://www.ibdfam.org.br/noticias/4862/novosite>. Acesso em 26/08/2016.

IBDFAM/Instituto Brasileiro de Direito de Família. Os limites da intervenção do Estado na vida privada. Disponível 
em: $<$ http://ibdfam.jusbrasil.com.br/noticias/2875868/os-limites-da- intervencao-do-estado-na-vida-privada>; acesso em 20 de novembro de 2015, ás $11: 10$.

IBDFAM/Instituto Brasileiro de Direito de Família. Rio de Janeiro registra a primeira união entre três mulheres. 21/10/2015. Fonte: Assessoria de Comunicação do IBDFAM com informações do Espaço Vital. Disponível em:< http://www.ibdfam.org.br/noticias/5814/Justi\%C3\%A7a+carioca+oficializa+a+primeira+uni

\%C3\%A3o+entre+tr\%C3\%AAs+mulheres>; disponível em 23 de julho de 2016, ás 12:43.

IBDFAM./ Instituto Brasileiro de Direito de Família. Rio de Janeiro registra mais uma união poliafetiva. Instituto Brasileiro de Direito de Família, 06/04/2016. Disponível em:< http://www.ibdfam.org.br/noticias/5961/Rio+de+Janeiro+registra+mais+uma+uni\%C3\%A3o+poliafetiva>; acesso em 29 de agosto de 2016, ás 01:29.

IBDFAM. Instituto Brasileiro de Direito de Família. Tabeliã diz que registro de união poliafetiva é evolução do Direito de Família. 19/04/2016. Disponível em: $<$ http://www.ibdfam.org.br/noticias/na-midia/11301>; acesso em 02 de setembro de 2016; às 13:30.

IBDFAM/ Instituto Brasileiro de Direito de Família. Tabeliã do Rio de Janeiro se dispõe a realizar uniões estáveis poliafetivas

Disponível em: $<$ http://www.sead.univasf.edu.br/mooc/modelo.php?link=curso $>$; acesso em 03/09/2016; ás 10:39.

IBDFAM/Instituto Brasileiro de Direito de Família. Trio registra união em cartório de Tupã.

24/08/2012

Fonte: Jornal o

Estado de

S. Paulo. Disponível dfam.org.br/noticias/ibdfam-naem: $<\quad$ http://www.ibtra+uni $\% \mathrm{C} 3 \% \mathrm{~A} 3 \mathrm{o}+\mathrm{em}+\mathrm{cart} \% \mathrm{C} 3 \% \mathrm{~B} 3 \mathrm{rio}+\mathrm{de}+\mathrm{Tup} \% \mathrm{C} 3 \% \mathrm{~A} 3>$; acesso em 20 de julho de 2016; ás 15:55.

IBDFAM. Instituto Brasileiro de Direito de Família. União afetiva entre três pessoas é oficializada em escritura pública. 22/08/2012. Disponível em:< http://www.ibdfam.org.br/noticias/ibdfam-nadia/6381/+Uni\%C3\%A3o+afetiva+entre+tr\%C3\%AAs+pessoas+\% $3 \% \mathrm{~A} 9+$ ficializada+e m+escritura+p\%C3\%BAblica>; acesso em 03 de setembro de 2016, ás 13:23.

IBDFAM/ Instituto Brasileiro de Direito de Família. União poliafetiva: escritura é necessária?. 20/04/2016. Disponível em:<http://www.ibdfam.org.br/noticias/5970>; acesso em 26 de agosto de 2016; ás 14:43.

IBDFAM na mídia. Fórum - União poliafetiva. Brasília, TV Justiça, 2012. Programa Televisivo. Supremo TribunalFederal. Disponível em:< http://www.ibdfam.org.br/noticias/ibdfam-na-mi$\mathrm{dia} / 6528 / \mathrm{F} \% \mathrm{C} 3 \% \mathrm{~B} 3 \mathrm{rum}+-$

+Uni\%C3\%A3o+poliafetiva+>; acesso em 03 de setembro de 2016, ás 11:44. 
LOBO , Paulo Direito civil : famílias / Paulo Lôbo. - 4. ed. - São Paulo : Saraiva, 2011. - (Direito civil).

MAIA, Isabela Rebouças; CARNEIRO, Wálber Araújo. O que é isto?- Ponderação de Princípios. XII SEPA - Seminário Estudantil de Produção Acadêmica, UNIFACS, 2013.

MARIN, Jeferson Dytz. Direitos fundamentais e democratização do afeto: uma incursão pelo princípio da livre orientação sexual. In: MINHOTO, Antônio (Org.). Constituição, minorias e inclusão social. São Paulo: Rideel, 2009.

Os diferentes tipos de relacionamento que vão além do padrão "Amor Romântico". Amores Livres. Rio de Janeiro, GNT, 2015. Série Televisiva. Direção: João Jardim.

PEREIRA, Rodrigo da Cunha. Afeto, Ética, Família e o novo Código Civil. Belo Horizonte: Del Rey, 2004.

STRECK, Lênio Luiz. O que é isto: decido conforme a minha consciência?. Porto Alegre: Livraria do Advogado, 2011.

SUPREMO TRIBUNAL FEDERAL. ADPF 132: Arguição de Descumprimento de Preceito Fundamental. Relator(a): Min. Ayres Britto. Disponível em: $<$ http://www.stf.jus.br/portal/peticaoInicial/verPeticaoInicial.asp?base=ADPF\&s1=132\&processo=132>; acesso em 19/07/16, às23h15min.

SUPREMO TRIBUNAL FEDERAL. ADI 4277/DF. Ação Direta de Inconstitucionalidade. Disponível em: < http://www.stf.jus.br/portal/geral/verPdfPaginado.asp?id=400547\&tipo=TP\&descricao=ADI\%2F4277>; acesso em 26 de setembro de 2016, às 20:11.

TIZZO, Luis Gustavo Liberato, BERTOLINI, Priscila Gomes Caroline. Das Uniões Poliafetivas Hoje: Uma Análise á Luz Da Publicização do Privado e Acesso á Justiça. Disponível em:< http://www.publicadireito.com.br/artigos/?cod. =b8b6674d4052e35e > ; acesso em 27 de outubro de 2010.

VAUGHAN, Peggy. O mito da monogamia: uma nova visão dos casos amorosos e como sobreviver a eles, tradução Nathanael Caixeiro. Rio de Janeiro: Rosa dos Tempos, 1991.

VECCHIATTI, Paulo Roberto Iotti. União Estável Poliafetiva: Breves Considerações acerca de sua constitucionalidade. Disponível

em: $<\quad$ http://www.arpensp.org.br/?pG=X19leGliZV9ub3RpY2lhcw==\&in=MTcwODk=\&filtro=2)>. Acesso em 27 de outubro de 2015. 